Supporting Information for:

\title{
Au Nanoparticles Encapsulated in Ru Carbonyl Carboxylate Shells
}

Suhua Wang and Wee-Sun Sim*

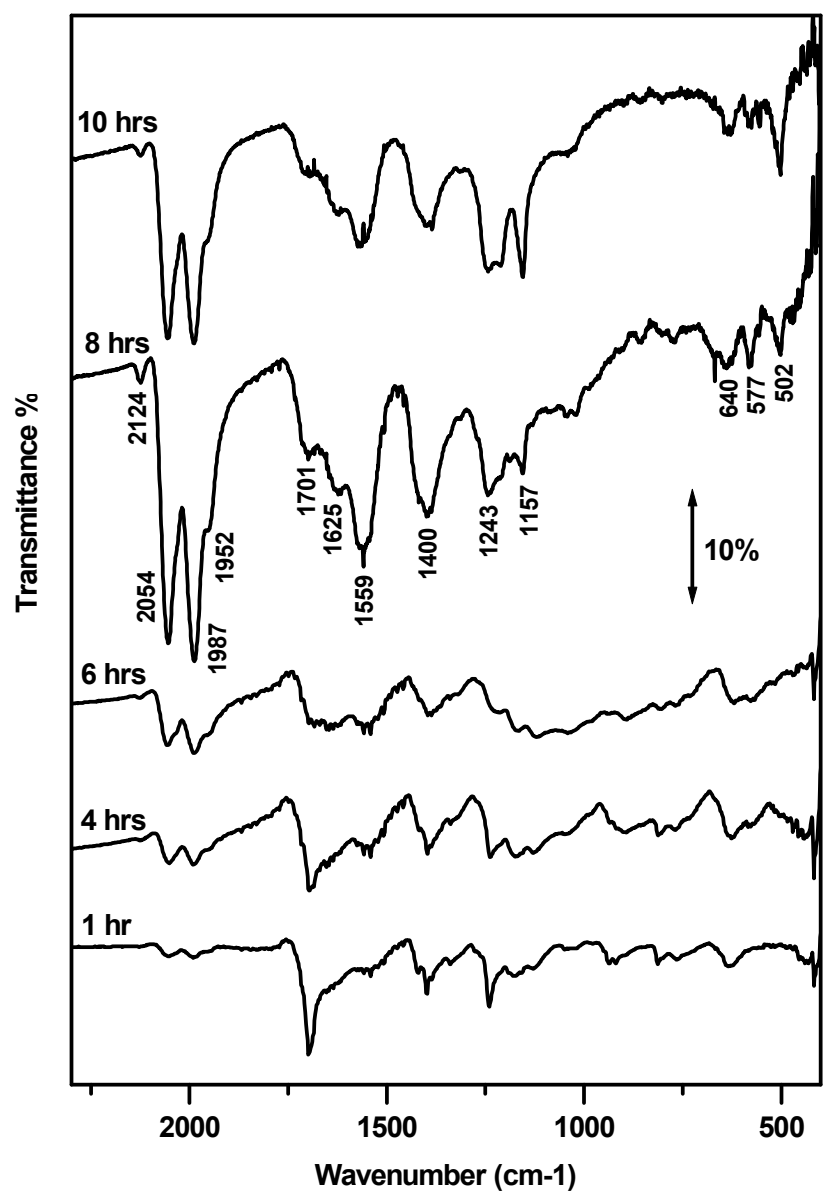

Figure 1. Infrared spectra of the reaction product between MPA-capped Au nanoparticles and $\mathrm{Ru}_{3}(\mathrm{CO})_{12}$ over a range of reaction times.

The extent of surface functionalization was judged on the basis of the conversion of free carboxyl groups of MPA $\left(\mathrm{C}=\mathrm{O}\right.$ stretching band at $\left.1700 \mathrm{~cm}^{-1}\right)$ into Ru-bound carboxylate groups of the complex (asymmetric and symmetric OCO stretching bands at 1559 and $1400 \mathrm{~cm}^{-1}$ ) and Ru-bound carboxyl groups of MPA $\left(\mathrm{C}=\mathrm{O}\right.$ stretching band at $\left.1625 \mathrm{~cm}^{-1}\right)$, and also on the relative proportion of carbonyl groups (CO stretching bands between 2150-1950 $\mathrm{cm}^{-1}$ ) incorporated. It is clear from the spectral sequence that the relative ratios of these bands are optimized around 8-10 hours with little change over that period. In fact, all the absorption bands the 8 and 10-hour spectra have identical wavenumbers 
(albeit with slight differences in the relative intensities of some bands) indicating that the surface species capping the Au nanoparticles are the same, and that the reaction is essentially complete by 8 hours. The bands at 1243 and $1157 \mathrm{~cm}^{-1}$ arise from the $\mathrm{C}-\mathrm{O}$ stretching and $\mathrm{C}-\mathrm{C}$ stretching/ $\mathrm{CH}_{2}$ bending of both free and Ru-bound carboxyl groups of MPA, while the $502 \mathrm{~cm}^{-1}$ band is attributed to the Ru-O stretching of the Ru-bound carboxylate groups of the complex and the Ru-bound carboxyl groups of MPA. As the reaction proceeds, one would thus expect the following trends in the relative intensities of the bands, which is what is observed.

\begin{tabular}{|l|l|l|l|l|l|l|}
\hline $\begin{array}{l}\text { Wavenumber } \\
\left(\mathrm{cm}^{-1}\right)\end{array}$ & $\begin{array}{l}2150- \\
1950\end{array}$ & 1700 & 1625 & $1559 / 1400$ & $1243 / 1157$ & 502 \\
\hline Relative intensity & increases & decreases & increases & increases & $\begin{array}{l}\text { decreases } \\
\text { then } \\
\text { increases * }\end{array}$ & increases \\
\hline
\end{tabular}

* assuming that the dyamic dipole moments and hence infrared absorption intensities of these vibrational modes of the Ru-bound MPA molecules are larger than those of free MPA. 

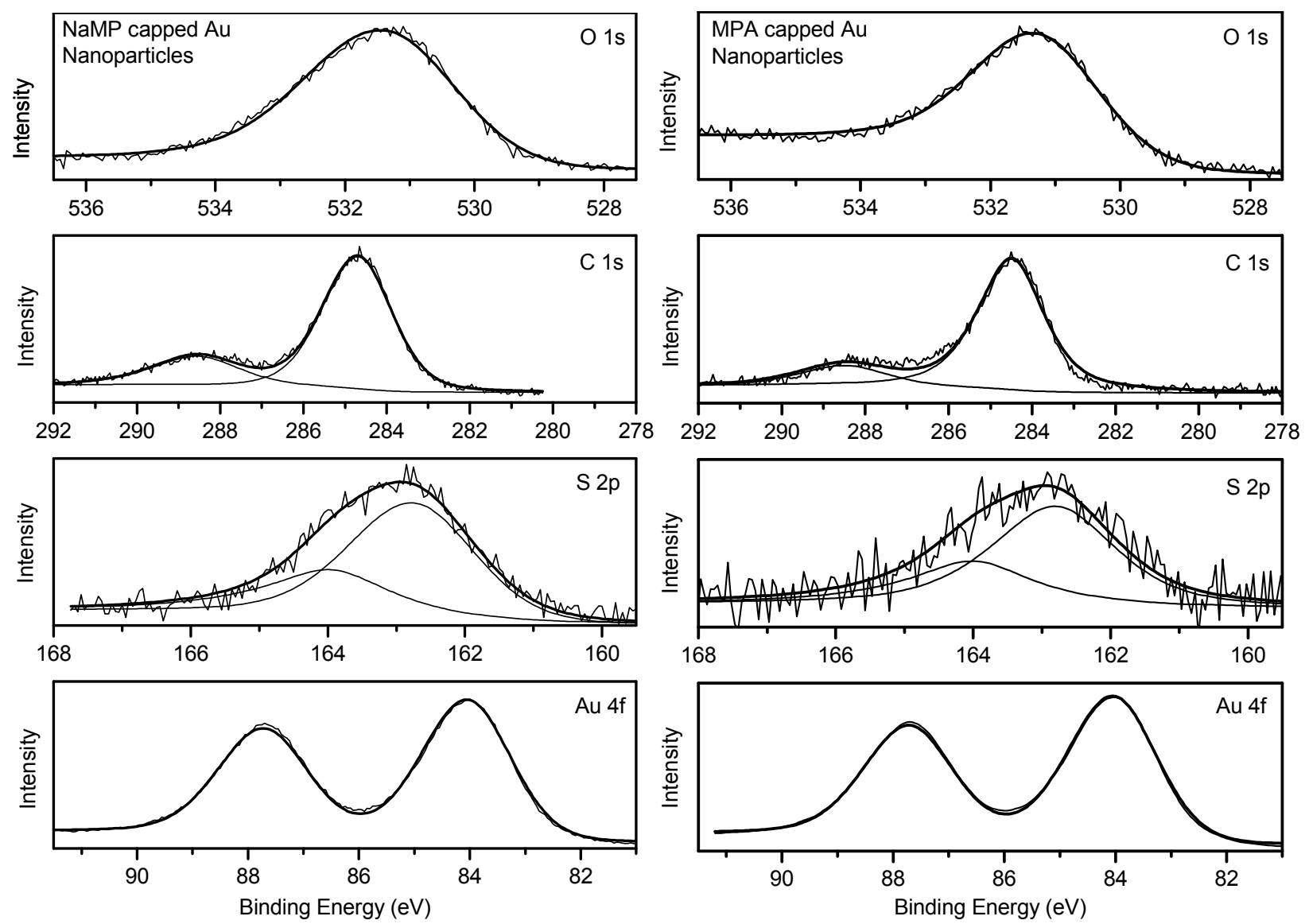

Figure 2. XPS spectra of NaMP- and MPA-capped Au nanoparticles.

The binding energies and assignment of the fitted component peaks for both types of nanoparticles are identical and are tabulated below:

\begin{tabular}{|l|l|l|l|l|l|}
\hline Binding Energy $(\mathrm{eV})$ & 531.3 & 288.5 & 284.4 & $162.8 / 164.0$ & $84.0 / 87.8$ \\
\hline Assignment & O from & $\mathrm{C}$ from & C from alkyl chain & $\mathrm{S} 2 p_{3 / 2}$ and & $\mathrm{Au} 4 f_{7 / 2}$ and \\
& $\begin{array}{l}\text { carboxyl/ } \\
\text { carboxylate }\end{array}$ & carboxylate & hydrocarbon & $\mathrm{S} 2 p_{1 / 2}$ from & $\mathrm{Au} 4 f_{5 / 2}$ from \\
& thiolate & metallic Au \\
& groups & groups & contamination & groups & core \\
\hline
\end{tabular}

